\title{
Evaluation of the Solubility of the HPMC/PVA Blends in Biological Fluids in vitro
}

\author{
Sara Elis Bianchi ${ }^{\mathrm{a}}$, Valeria Weiss Angeli, Kellen Cristhinia Borges de Souza ${ }^{\mathrm{a}}$, Diogo dos Santos Miron, \\ Gláucio de Almeida Carvalho ${ }^{\mathrm{b}}$, Venina dos Santos ${ }^{\mathrm{b}}$, Rosmary Nichele Brandalise ${ }^{\mathrm{b} *}$ \\ ${ }^{a}$ Centro de Ciências da Saúde, Universidade de Caxias do Sul - UCS, \\ Rua Francisco Getúlio Vargas, 1130, Bairro Petrópolis, Caxias do Sul, RS, Brazil \\ ${ }^{\mathrm{b}}$ Centro de Ciências Exatas e Tecnologia, Universidade de Caxias do Sul - UCS, \\ Rua Francisco Getúlio Vargas, 1130, Bairro Petrópolis, Caxias do Sul, RS, Brazil
}

Received: September 22, 2010; Revised: April 28, 2011

\begin{abstract}
Polymers are often used to coat tablets for controlled drug release. The purpose of this study is to evaluate the solubility of the HPMC and PVA blend compared to isolated polymers in solutions with a pH of biological fluids (6 and 1.2) and the dissolution of capsules obtained using theophylline granules produced with the HPMC/ PVA 25/75 blend as a matrix and as coating. HPMC is completely solubilized in the medium that simulates the $\mathrm{pH}$ of the stomach and intestine, and PVA is the polymer that allows controlling the solubility of the blend in the medium, with a differents $\mathrm{pH}$. The dissolution time was monitored by UV absorbance with maximum theophylline at $269 \mathrm{~nm}$. The theophylline was released immediately in the granules, and in the capsules $78.4 \%$ after 30 minutes and $97.4 \%$, after 120 minutes. Thus, PVA can potentially control the drug solubilization, contributing to obtaining modified release systems.
\end{abstract}

Keywords: HPMC, PVA, theophylline, granules, capsules, solubility

\section{Introduction}

New alternative technologies are sought to reduce the adverse effects of some drugs and maintain the stability of active substances associated with different pharmaceutical forms.

Polymers are widely used in pharmaceutics. The mechanism and kinetics of drug release are based on solubility, swelling and polymer erosion properties ${ }^{1,2}$.

Water-soluble drugs are released mainly by diffusion with a limited contribution of matrix erosion and anomalous diffusion resulting from polymer chain relaxation ${ }^{3}$.

The drug release profile changing solubilization time and maximizing bioavailability can be created using polymer blends with different solubilities in the $\mathrm{pH}$ of biological fluids.

Different pharmaceutical forms for oral use can be prepared for immediate release of the drug through the gastrointestinal tract or by controlling the release time.

Hydroxypropylmethylcellulose (HPMC) is widely used as a polymer for controlled drug release ${ }^{4,5}$. It is easily accepted, and has a variety of viscosities and types of substitution, and the necessary doses are easy to formulate ${ }^{6}$.

Poly(vinyl alcohol) (PVA) has been studied for use in drug release, since at a high content, can control the process release ${ }^{7}$.

As expected, the high percentage of water - soluble polymer can speed up drug release. Solubility, polarity, molar mass and polymer degradation parameters, when known and controlled, have contributed to progress in drug release efficiency studies to minimize the side effects of its consumption in human beings ${ }^{8}$.

The drug used in this experiment was theophylline, utilized to treat bronchial asthma ${ }^{9,10}$.

The purpose of this study is to evaluate the dissolution properties of HPMC, PVA polymers and their blends in the $\mathrm{pH}$ of biological fluids, in-vitro, as well as monitoring morphological, thermal and structural properties of the HPMC/PVA blend. Dissolution was evaluated using capsules obtained with theophylline granules produced employing the HPMC/PVA 25/75 blend as a matrix and as coating.

\section{Materials and Methods}

\subsection{Materials}

Hydroxypropylmethylcellulose (HPMC) is manufactured by All Chemistry do Brasil Ltda and Poly(vinyl alcohol) (PVA) by Pharma Special. The brand of hydrochloric acid used is Vetec with $37 \%$ purity. The phosphoric acid used is Merck with $85 \%$ purity. USP ${ }^{11}$ standard theophylline and raw theophylline obtained from ASKY were used.

\subsection{Methods}

\subsubsection{Preparation of the HPMC/PVA blend and the films}

Blends of HPMC/PVA at the proportions of 75/25, 50/50 and $25 / 75(\mathrm{w} / \mathrm{w})$ were prepared and solubilized in water, in reactors at $80{ }^{\circ} \mathrm{C}$ with magnetic stirring for 20 minutes, so as to obtain a final solution of $5 \%$ polymer $(\mathrm{w} / \mathrm{w})$. Next the solutions were distributed in Petri dishes and dried in a Tecnal oven with air circulation, model TE-394/2, for 10 hours, until complete evaporation the water. The films formed were removed from the dishes using pincers and kept in hermetic containers until just before use as matrix and coating of the theophylline granules.

2.2.2. Production of theophylline granules and of capsules with HPMC/PVA - 25/75

Theophylline granules were prepared using the films with a higher percentage of PVA (HPMC/PVA 25/75) as matrix and coating agent. The films were milled in an IKA-Werke, model A11 basic cryogenic mill before being used as a matrix in the blend with theophylline. 
The HPMC/PVA 25/75 blend was chosen as matrix and coating due to the higher amount of PVA polymer, which has a low solubility in the system studied.

Table 1 show the composition used in the formulation of theophylline granules for the subsequent preparation of capsules.

Initially the theophylline was weighed and blended with the polymer matrix in a porcelain mortar. Next the agglutinant polymer solution was added, and then it was placed in a mini-granulator with a $2 \mathrm{~mm}$ sieve. The wet mass was dried at $55{ }^{\circ} \mathrm{C}$ for 20 minutes after ethanol (70\%) was applied.

The dried granules were transferred to a porcelain mortar and another portion of agglutinant solution was added.

The granules were forced through 24 mesh $(1.18 \mathrm{~mm})$ and 14 mesh $(0.72 \mathrm{~mm})$ sieves. The granules collected in the 14 mesh sieve were coated by adding agglutinant solution and dried at $55^{\circ} \mathrm{C}$ for 20 minutes. The process was repeated four times to obtain the theophylline coated granules.

The theophylline coated granules contained $51.3 \%$ of teophylline and $48.7 \%$ of HPMC/PVA $25 / 75$ (43.6 and 5.1\% as matrix and coating agent, respectively).The final granules were weighed and their apparent density $\left(\rho=m \cdot v^{-1}\right)$, determined by measuring the volume occupied by granules in a beaker.

\subsubsection{Characterization of the theophylline granules}

The flow, humidity and dosage of the theophylline granules were determined using the following methods: Ten $g$ of each granulate produced were weighed, and placed in a funnel to measure flow. With the help of graph paper, the angle of repose of each bead was calculated. This test was also performed with theophylline.

A standard curve was prepared for to quantify theophylline in the granules (theophylline concentrations of 2.5, 5.0 and $7.5 \mu \mathrm{g} \cdot \mathrm{mL}^{-1}$ in 0.1 mol. $\left.\mathrm{L}^{-1} \mathrm{HCl}\right)$.Two extraction methods in $\mathrm{HCl} 0.1$ mol. $\mathrm{L}^{-1}$ were proposed: the first using 1 minute of Maxiclean ultrasound, model 1450, manufactured by Unique, and the second method 20 minutes of mechanical agitation. Later, theophylline was dosed by a UVvisible spectrophotometer at a $269 \mathrm{~nm}$ wavelength. The formulations presented conflicting results and it was decided to test the extraction with 2 minutes of ultrasound.

The theophylline granules were encapsulated to obtain a $200 \mathrm{mg}$ dose, and microcrystalline cellulose was used as excipient. The capsules were assayed in a Nova Etica dissolutor, using $900 \mathrm{~mL}$ of $\mathrm{HCl} 0.1$ mol.L $\mathrm{L}^{-1}$ medium, basket apparatus, $50 \mathrm{rpm}$, and detection was carried out with a UV-visible spectrophotometer at a wavelength of $269 \mathrm{~nm}$.

\subsubsection{Characterization of the HPMC/PVA blend}

The phosphate and hydrochloric acid buffers used were prepared and standardized in the laboratory according to $\mathrm{USP}^{11} 30,2007$. The polymers and the blends, in the form of films, were weighed at a proportion of 1:30, in triplicate, and added to the buffer solution with $\mathrm{pH} 6.0$ and hydrochloric acid buffer with $\mathrm{pH} 1.2$, with continuous magnetic stirring for 40 minutes. After this period, the polymer solubility was observed in the mediums used.

Polymers HPMC and PVA and the blends were characterized by DSC in Shimadzu equipment, model DSC-50, with heating at $10{ }^{\circ} \mathrm{C} / \mathrm{min}$ and cooling at $20^{\circ} \mathrm{C} / \mathrm{min}$ and $\mathrm{N}_{2}$ flux of $50 \mathrm{~mL} / \mathrm{min}$. The approximately $10 \mathrm{mg}$ samples were heated from -40 to $230{ }^{\circ} \mathrm{C}$, followed by cooling at $-25{ }^{\circ} \mathrm{C}$. Indium and Tin was used as the standard reference material to calibrate the temperature and energy scales of the DSC instrument.

The morphology of the polymers, their blends and theophylline granules were analyzed by Scanning Electron Microscopy (SEM) in Superscan equipment, model SS-550. The samples to be analyzed were fractured in liquid nitrogen, coated with gold and preserved in a desiccator. The granules were not fractured in liquid nitrogen, but they were coated with gold and preserved in a dessicator.

The polymers used in the study were analyzed by Spectrometry in the Fourier Transform Infrared Region (FTIR), in the form of films obtained in an aqueous solution at $80^{\circ} \mathrm{C}$, and later evaporated in the oven with air circulation at $60{ }^{\circ} \mathrm{C}$. The spectrophotometer used is a Thermo Electron Nicolet, model iS10, with an analysis in the region of 4000 to $650 \mathrm{~cm}^{-1}$ using Attenuated total reflectance (ATR).

Evaluation of the dissolution of capsules containing theophylline granules

The capsules were produced and detection was carried out with UV-visible spectrophotometer at a $269 \mathrm{~nm}$ wavelength. The samples from the dissolutor, in 30 and 120 minutes, were diluted to adjust the concentration to the standard curve (4.0-6.0 $\mu \mathrm{g} \cdot \mathrm{mL}^{-1}$ of theophylline).

\section{Results and Discussion}

The polymer and blend characteristics were evaluated with respect to changes observed in their chemical structure, variations in morphology and solubility in different mediums that simulate the $\mathrm{pH}$ of the stomach and intestine.

Figure 1 presents the infrared spectra of HPMC, PVA and their blends.

Both polymers showed strong bonded hydroxyl bands ( $\mathrm{n}=3200-3600 \mathrm{~cm}^{-1}$ ) and the typical C-H alkyl stretching band $\left(\mathrm{n}=2850-3000 \mathrm{~cm}^{-1}\right)$. The region of $1120-1020 \mathrm{~cm}^{-1}\left(\mathrm{v}_{\mathrm{C}-\mathrm{O}-\mathrm{C}}\right)$ presented coincident bands for both polymers ${ }^{12}$. However HPMC and PVA and their blends can be differentiated by a sharp carbonyl band in $1700 \mathrm{~cm}^{-1}$ which is observed only when PVA is presented. New absorption bands were not observed in the blends.

Table 1. Composition of the theophylline granule with HPMC/PVA 25/75.

\begin{tabular}{ccc}
\hline Component & Function & Concentration $(\%)$ \\
\hline Teophylline & Active principle & 51.3 \\
HPMC/PVA & Matrix & 43.6 \\
HPMC/PVA & Agglutinant/Coating & 5.1 \\
\hline
\end{tabular}

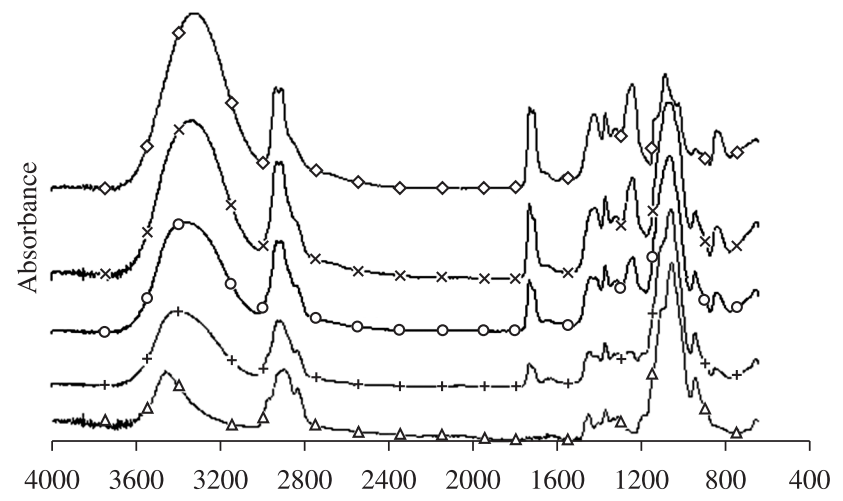

Wavenumber $\left(\mathrm{cm}^{-1}\right)$

\begin{tabular}{|c|c|}
\hline$\leadsto$ HPMC/PVA $0 / 100$ & * HPMC/PVA $25 / 75$ \\
\hline - - HPMC/PVA 50/50 & 十 HPMC/PVA 75/25 \\
\hline$\triangle-$ HPMC/PVA $100 / 0$ & \\
\hline
\end{tabular}

Figure 1. FTIR spectra of HPMC, PVA and their HPMC/PVA blends with 75/25, 50/50 and 25/75 compositions. 
Figure 2 shows the thermal behavior of HPMC, PVA and their HPMC/PVA blends, containing 25, 50 and $75 \%$ of PVA in the interval from -25 to $210^{\circ} \mathrm{C}$, during the heating of the DSC.

The thermogram of HPMC presents two enthalpy heat absorption events, one at $105.2{ }^{\circ} \mathrm{C}$ attributed to the removal of humidity ${ }^{13}$, and the other at $167.9^{\circ} \mathrm{C}$, the latter attributed to the fusion event. The PVA also presented two enthalpy events, one at $115.7^{\circ} \mathrm{C}$, characteristic of the humidity of this material, and the second at $183.3^{\circ} \mathrm{C}$ attributed to its fusion. In the latter event we see a less intense event superposed at $176.4{ }^{\circ} \mathrm{C}$. These temperatures are different from the PVA fusion interval in the literature, which is from 218 to $258^{\circ} \mathrm{C}^{14}$. For HPMC the onset fusion event occurred at 154 and endset at $178{ }^{\circ} \mathrm{C}$. The PVA onset fusion was at 176 and endset at $195{ }^{\circ} \mathrm{C}$, but when one considers the event less intense, the onset of the fusion process occurs at $159.4{ }^{\circ} \mathrm{C}$.

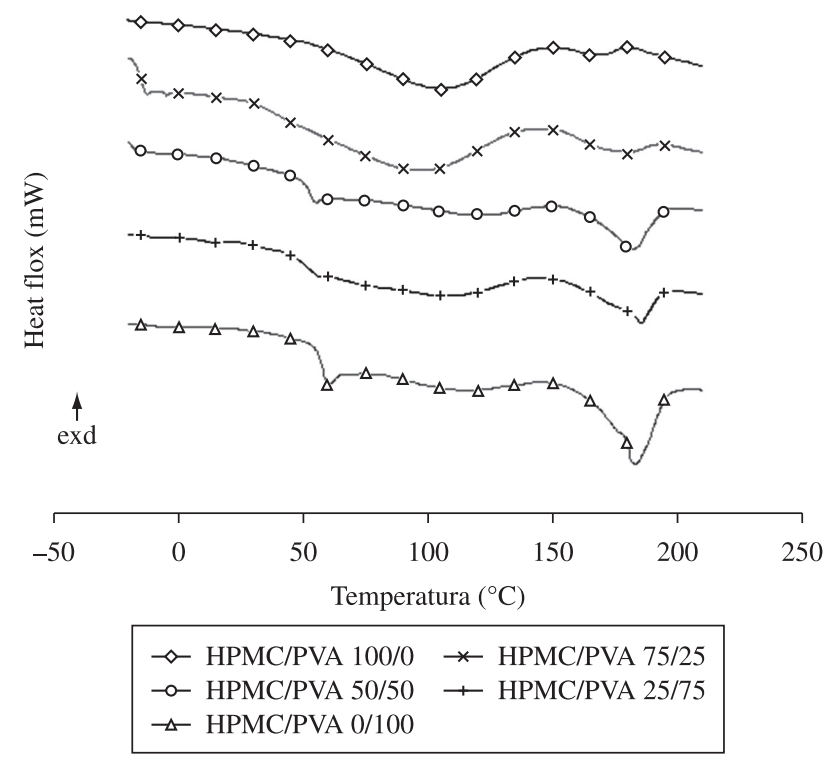

Figure 2. Curves of DSC of HPMC of PVA and their HPMC/PVA blends with $75 / 25,50 / 50$ and 25/75 compositions.

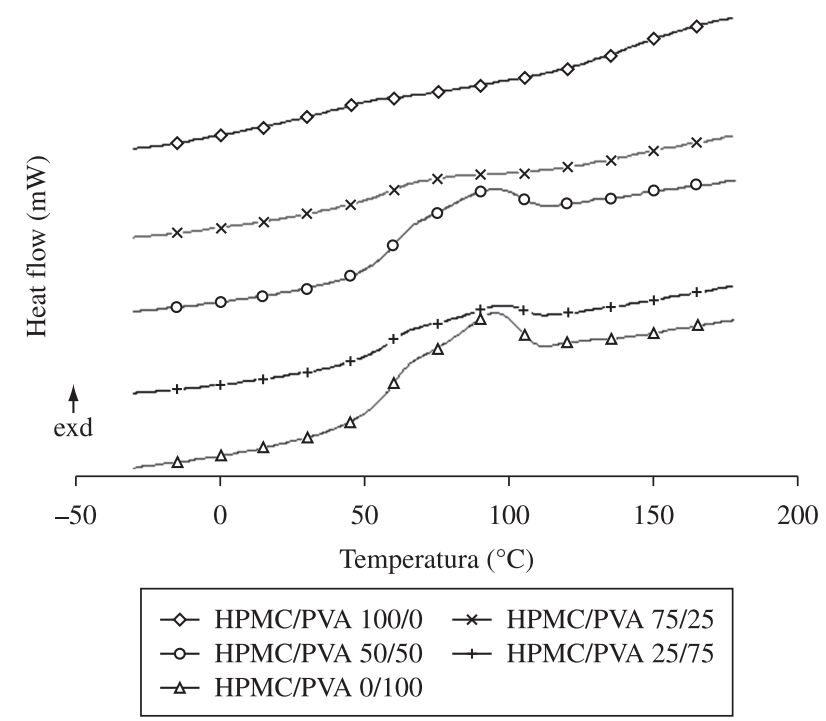

Figure 3. Curves of the DSC thermograph in cooling HPMC and its blends with PVA HPMC/PVA with 75/25, 50/50 and 25/75.
In the blends there was a displacement from onset of the fusion process to higher temperatures, with an increased PVA content of 154, 166 and $177^{\circ} \mathrm{C}$, respectively, for the compositions 75/25, 50/50 and $25 / 75$, but the endset fusion process was practically unchanged in the blends, with a trend to a rise in temperature as the PVA content increased.

It can be observed that the fusion event of the two polymers is close, with superposition, and it is therefore difficult to analyze the compatibility between the blends and crystallinity studies. A glass transition event is observed at $63.6^{\circ} \mathrm{C}$ for PVA and also in the HPMC/ PVA 50/50 and 25/75 blends.

The electronic micrographs and calorimetric curves showed incompatibility between the blends, but with a possible interference of HPMC in the PVA fusion process. Demappa et al., 2008, say that the blends of HPMC and PVA are miscible above $60 \%$ HPMC $^{15}$.

Figure 3 shows the exothermal curves of DSC of HPMC, PVA and their HPMC/PVA blends containing 25, 50 and $75 \%$ of PVA in the interval from -30 to $180{ }^{\circ} \mathrm{C}$

During cooling the samples presented a similar interference to that observed during heating, where the HPMC events were obscured

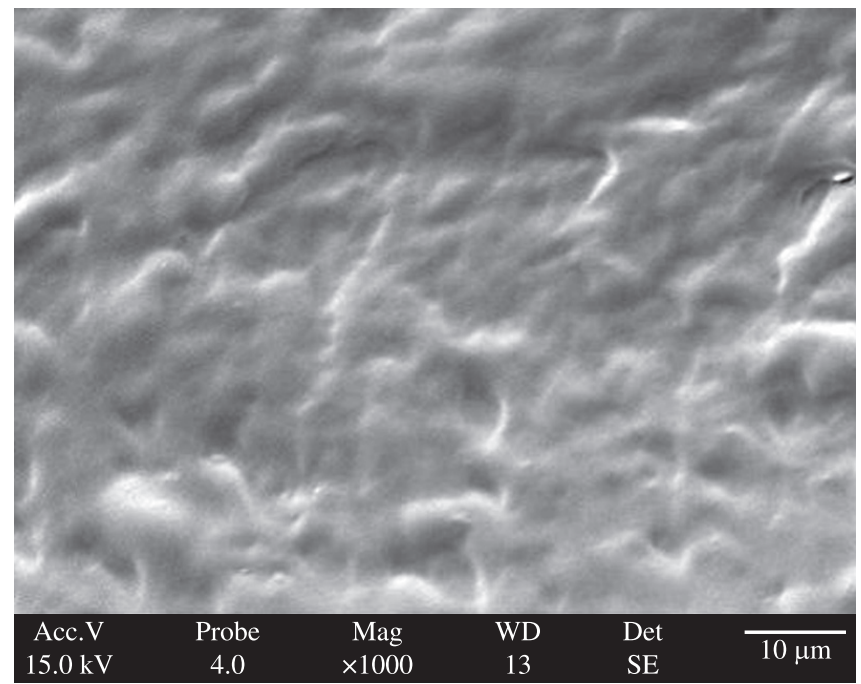

HPMC

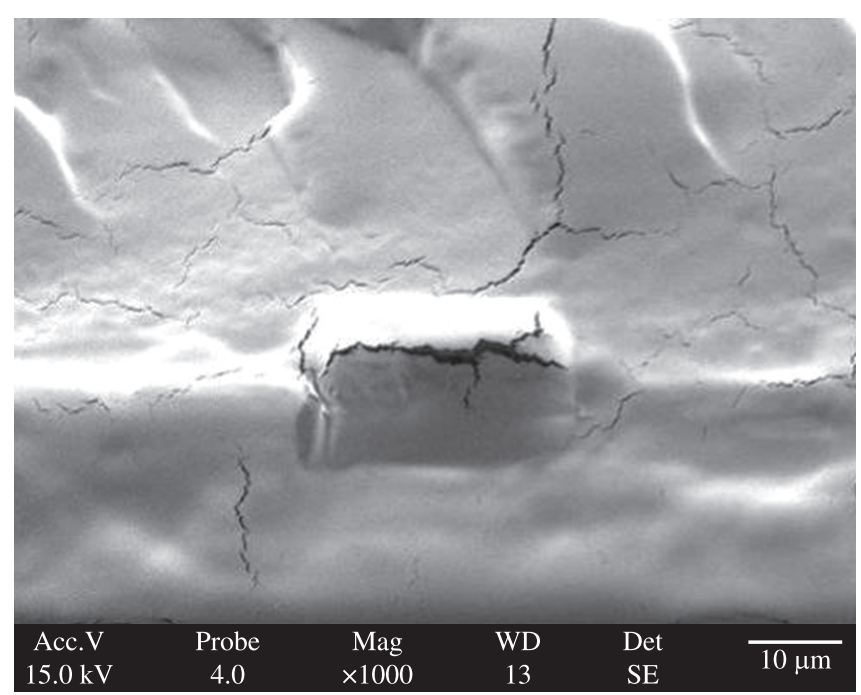

PVA

Figure 4. Micrographs of polymers HPMC and PVA (1000x). 


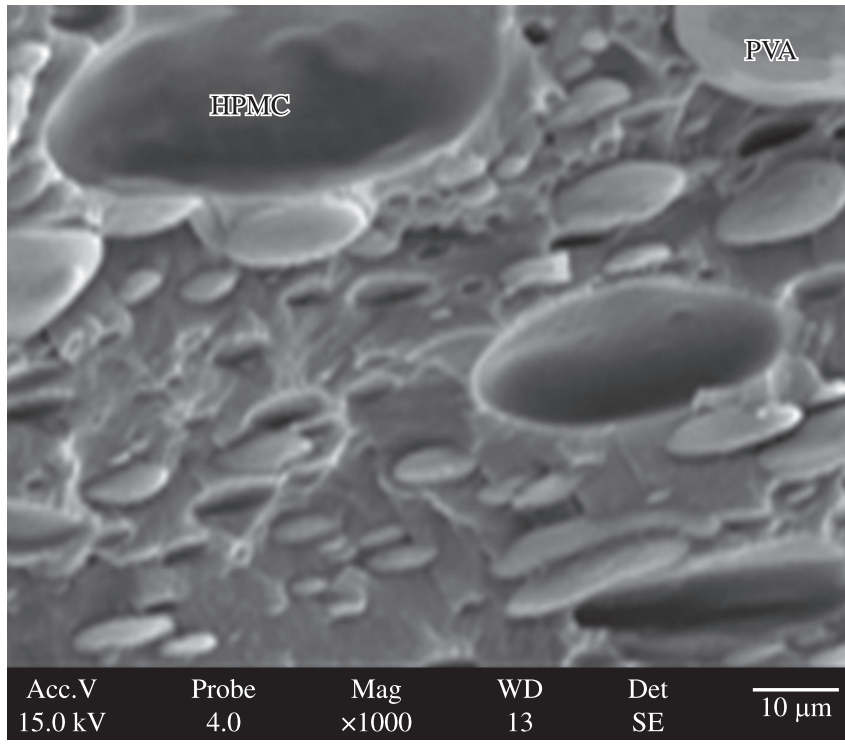

(a) $75 / 25$

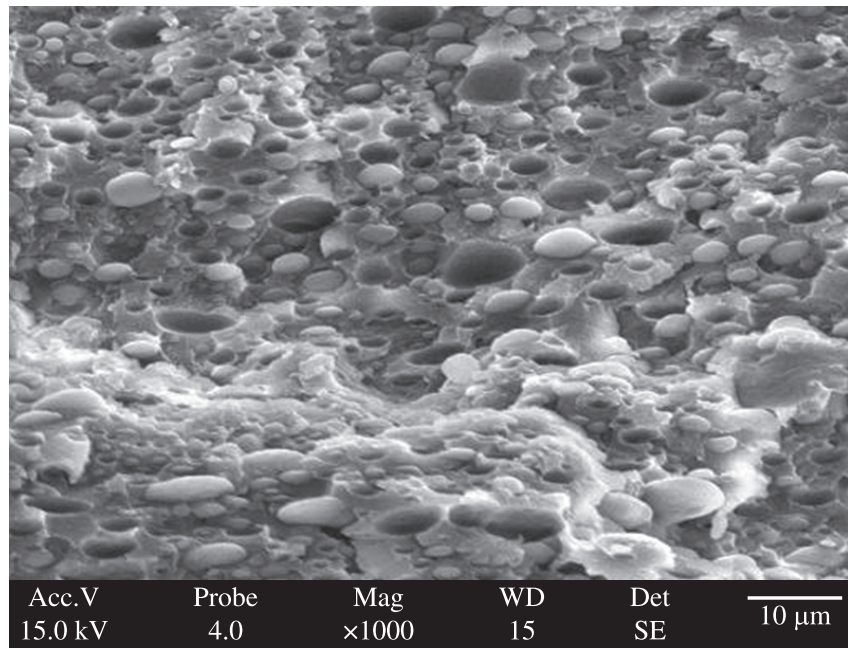

(b) $50 / 50$

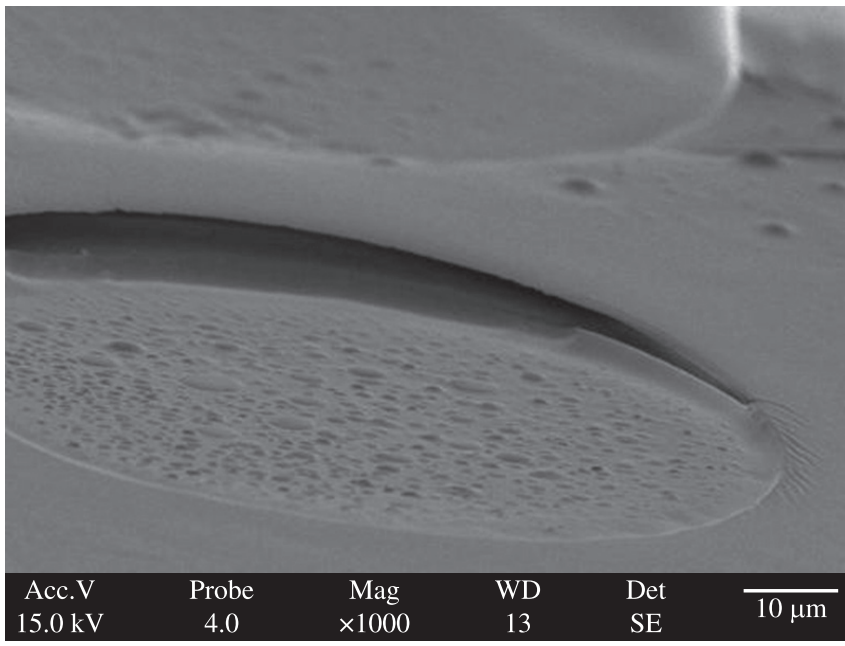

(c) $25 / 75$

Figure 5. Micrographs for the HPMC/PVA blends a) $75 / 25$, b) 50/50, c) $25 / 75$ (1000x). by the PVA events. HPMC presented crystallization $\left(\mathrm{T}_{c}\right)$ at $50.1{ }^{\circ} \mathrm{C}$ and the event ranged from 81.6 to $28.4{ }^{\circ} \mathrm{C}$. The onset crystallization temperature $\left(\mathrm{T}_{\mathrm{c}}\right)$ of PVA was $109.1{ }^{\circ} \mathrm{C}$. Its maximum peak was at $94.2^{\circ} \mathrm{C}$ and endset at $75.5^{\circ} \mathrm{C}$, immediately followed by the freezing event of the amorphous phase that occurred at the mid point at $55.7^{\circ} \mathrm{C}$, and onset at 65.2 , endset at $49.25^{\circ} \mathrm{C}$.

Crystallization processes were observed in all blends. Only the HPMC/PVA blend at a 75/25 ratio behaved similarly to the crystallization process of pure HPMC, but at a lower temperature, with onset at $105.1^{\circ} \mathrm{C}$, peak temperature at $69.8^{\circ} \mathrm{C}$ and endset at $47.94{ }^{\circ} \mathrm{C}$. The other blends behaved like pure PVA, with the crystallization event followed by freezing, in the same order and temperature range.

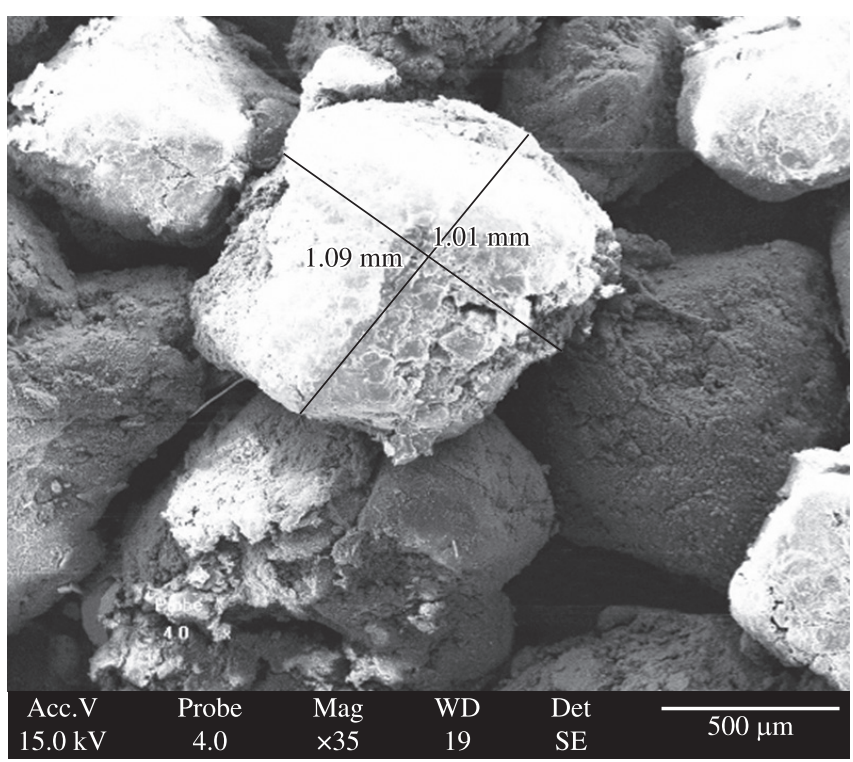

(a) $35 x$

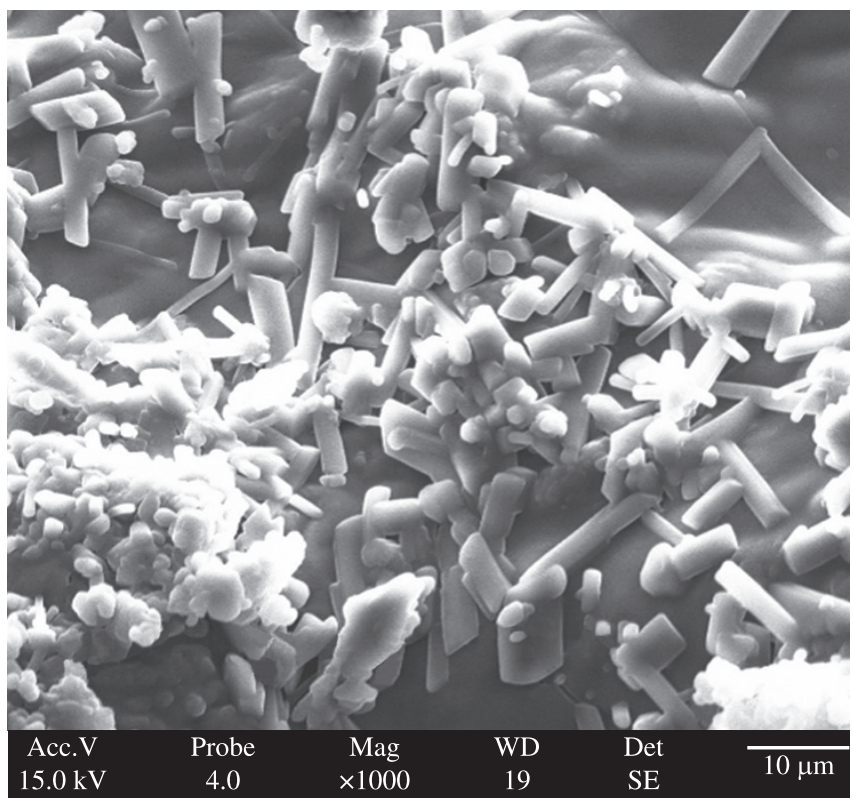

(b) $1000 x$

Figure 6. Micrographs for theophylline granules based on a HPMC/PVA blend $25 / 75$ a) $35 \times$, b) $1000 x$. 
The Figure 4 and 5 shows the micrograph of the fractured surface of test specimens of polymers HPMC and PVA and blends of HPMC and PVA, with a composition of 75/25, 50/50 and 25/75, respectively.

The observation of domains involving PVA and HPMC is clear, and indicates the immiscibility of the blend (Figure 4).

The interface compatibility between the components is one of the main factors affecting blend performance ${ }^{16}$. In the 75/25 composition, with $75 \%$ of HPMC as a matrix, and in 50/50, the separation of phases is more visible, compared to a composition of $25 / 75$, whose matrix is the PVA, with less evidence of domains, presenting the best synergy between the components of the blend.

Figure 6 illustrates the micrographs of the theophylline granules from a blend with HPMC/PVA 25/75.

It was possible to manufacture the granules using the blend but the granule coating was not homogeneous. After the granulation process, regions characteristic of HPMC/PVA could be seen on the granule surface. However, these regions are intercalated by distinct domains of the polymers that make up the blend (Figure 6b).

The results obtained by analyzing the solubility of the HPMC, PVA polymers pure and their blends, in different mediums, are show in Table 2.

According to Demappa ${ }^{15}$ et al., 2008, the blend HPMC/PVA $(1 \% \mathrm{w} / \mathrm{w})$ is miscible in water, for contents above $60 \% \mathrm{HPMC}$, at temperatures of 30 and $50{ }^{\circ} \mathrm{C}$. The solubility results showed that HPMC presents good solubility in the buffers used, while PVA does not have the same profile.

The films containing HPMC/PVA 25/75 are less soluble in the $\mathrm{HCl}$ solution which simulates stomach fluid with $\mathrm{pH} 1.2$, and $\mathrm{pH}$ 6.0 of the intestine than in the films with high amounts of HPMC. For these reason, granules with HPMC/PVA 25/75 were prepared to modify theophylline release. The dissolution test described for theophylline in Brazilian Pharmacopeia (2003) was used to evaluate the release of theophylline from the granules The results obtained by analyzing the dissolution of capsules containing theophylline granules

Table 2. Solubility of polymers HPMC, PVA and their HPMC/PVA blends in the phosphate and hydrochloric acid buffer solutions, $\mathrm{pH} 6.0$ and 1.2 respectively for a 40 minutes period.

\begin{tabular}{ccc}
\hline Samples & $\begin{array}{c}\text { Phosphate buffer } \\
\text { pH 6.0 - intestine }\end{array}$ & $\begin{array}{c}\text { Hydrochloric acid } \\
\text { buffer pH 1.2 - stomach }\end{array}$ \\
\hline HPMC/PVA 100/0 & Soluble & Soluble \\
HPMC/PVA 75/25 & Soluble & Soluble \\
HPMC/PVA 50/50 & Soluble & Soluble \\
HPMC/PVA 25/75 & Partially soluble & Partially soluble \\
HPMC/PVA 0/100 & Partially soluble & Partially soluble \\
\hline
\end{tabular}

Table 3. Characteristics of theophylline granules with HPMC/PVA 25/75 in the matrix and coating.

\begin{tabular}{lc}
\hline Characteristics & Granules \\
\hline Flow $\left(^{\circ}\right)$ & 47.0 \\
Density $\left(\mathrm{g} \cdot \mathrm{mL}^{-1}\right)$ & 0.415 \\
Humidity $(\%)$ & 2.3 \\
Theoretical income $(\%)$ & 51.3 \\
Dosage* $(\%)$ & 94.7 \\
Dosage** $(\%)$ & 92.0 \\
Dosage*** $(\%)$ & 99.1 \\
\hline
\end{tabular}

*20 minutes of magnetic stirring; $* * 1$ minute of ultrasound; $* * 2$ minutes of ultrasound. showed that $78.4 \%$ of the drug was released after 30 minutes and $97.4 \%$ after 120 minutes.

The characteristics of granules such as flow, density, humidity, and dosage are presented in Table 3.

Table 3 shows the results that characterize theophylline granules and the different dosage results. The granules presented a better flux than the raw theophylline (angles of rest $47^{\circ}$ and $60^{\circ}$ for the granules and theophylline, respectively). The largest particle size of the granules justifies the better flux, and consequently the smaller angle of rest. The density and humidity found were as expected for medication granules. Different extraction methods were used to quantify theophylline in the granules. The method that uses two minutes of extraction by ultrasound was significantly different from the other methods $(\mathrm{p}<0.05)$ and it was used to dose the theophylline granules and capsules.

\section{Conclusions}

The purpose of this study was to prepare and characterize blends with HPMC/PVA in order to modify the physicochemical properties of the pure polymers and their applicability in drug release.

HPMC and PVA showed similar absorption bands in the FTIR. The beginning of the fusion process increased with the increase of PVA in the blends. During the PVA crystallization process the HPMC crystallization process was superposed. The HPMC/PVA blend was immiscible in the compositions tested, but composition 25/75, whose matrix is PVA, presented the least evidence of domains, presenting the best synergy between the components.

The morphological evaluation of the granules developed with theophylline and the HPMC/PVA 25/75 blend led to the conclusion that granulates could be obtained, but the granule coating was not homogeneous.

HPMC is completely solubilized in the medium that simulates the $\mathrm{pH}$ of the stomach and intestine, and PVA is the polymer that allows controlling the solubility of the blend in the medium, with a different $\mathrm{pH}$.

Finally, the theophylline granule dissolution test showed the potential of HPMC/PVA 25/75 films to modify drug release.

\section{Acknowledgements}

University of Caxias do Sul, BIC / UCS; VITAMED Company.

\section{References}

1. Conti S, Gaisford S, Buckto G, Conte U. Solution calorimetry to monitor swelling and dissolution of polymers and polymer blends. Thermochimica Acta. 2006; 450:56-60. doi:10.1016/j.tca.2006.07.017

2. Goissis G, Souza MH. Characterization and vitro release studies of tetracycline and rolitetracycline immobilized on anionic collagen membranes. Material Research. 2009; 12(1):69-74.

3. Hardy IJ, Windberg B, Neri C, Byway PV, Booth SW, Fitzpatrick S. Modulation of drug release kinetics from hydroxypropyl methyl cellulose matrix tablets using polyvinyl pyrrolidone. International Journal of Pharmaceutics. 2007; 337:246-253. PMid:17306477. doi:10.1016/j. ijpharm.2007.01.026

4. Konno H, Handa T, Alonzo D, Yaylor L. Effect of polymer type on the dissolution profile of amorphous solid dispersions containing felodipini. European Journal of Pharmaceutics and Biopharmaceutics. 2008; 70(2):493-499. PMid:18577451. doi:10.1016/j.ejpb.2008.05.023

5. Karavas E, Georgarakis E, Bikiaris D. Application of PVP/HPMC miscible blends enhanced mucoadhesive properties for adjusting drug release in predictable pulsatile chronotherapeutics. European Journal of Pharmaceutics and Biopharmaceutics. 2008; 64:115-126. PMid:16675210. doi:10.1016/j.ejpb.2005.12.013 
6. Mcphillips H, Craig DQM, Royal PG, Hill VL. Characterisation of the glass transition of HPMC using modulated differential scanning calorimetry. International Journal of Pharmaceutics. 1999; 180:83-90. doi:10.1016/S0378-5173(98)00407-4

7. Strübing S, Met H, Mäder K. Mechanistic analysis of drug release from tablets with membrane controlled drug delivery. European Journal of Pharmaceutics and Biopharmaceutics, 2006. In press.

8. Angeli VW, Guterres SS, Lucca F, Pohlmann, AR. Influence of benzyl benzoate as oil core on the physicochemical properties of spry-dried powders from polymeric nanocapsules containing indomethacin. Drug Delivery. 2000; 7:195-199. doi:10.1080/107175400455119

9. Yamaura SK, Sharif M. Preparation of theophylline hidrogels of atactic poly(vinyl alcohol) $\mathrm{Na} \mathrm{Cl} / \mathrm{H}_{2} \mathrm{O}$ system for drug delivery system. Journal of Controlled Release. 2002; 81:367-377. doi:10.1016/ S0168-3659(02)00085-8

10. Manjeshwar LS, Sullad AG, Aminabhavi MT. Polymeric Blend Microspheres for Controlled Release of Theophylline. Journal of Applied Polymer Science. 2010; 1361-1370.

11. United States Pharmacopeial Convention. USP NF 2007: The official compendia of standards. Rockville: United Pharmacopeial Convention, 2007. v. 1.
12. Reis EF, Campos FS, LageI AP, Leite RC, HeneineII LG, Vasconcelos WL et al. Synthesis and Characterization of Poly (Vinyl Alcohol) Hydrogels and Hybrids for rMPB70 Protein Adsorption. Materials Research. 2006; 9:185-191. doi:10.1590/S1516-14392006000200014

13. Ford JL. Thermal analysis of hydroxypropyl mehylcellulose and methylcellulose: powders, gels and matrix tablets. International Journal of Pharmaceutics. 1999; 179(2):209-228. doi:10.1016/ S0378-5173(98)00339-1

14. Charrier JM. Polymeric Materials and Processing. Canada: Hanser Publishers; 1990.

15. Chandralekha F, Lliger SR, Rao KP, Demappa T. Miscibility studies of HPMC/PVA blends in water by viscosity, density, refractive index and ultrasonic velocity method. Carbohydrate Polymers. 2008, 74:779-782. doi:10.1016/j.carbpol.2008.04.036

16. Wu S, Ji G, Shen J. A study on ultraviolet irradiation modification of high-density polyethylene and its effect in the compatibility of HDPE/PVA fiber composites. Materials Letters. 2003; 57:2647-2650. doi:10.1016/S0167-577X(02)01344-7 